\title{
Aplicación del arte a la investigación científica: fundamentos de un método original para su utilización
}

\author{
Applying art to scientific research: Reasons for using an original \\ method
}

Dr. Carlos G. Musso ${ }^{a}$, Mg. Débora Dricas ${ }^{b}$ y Mg. Henry González-Torres ${ }^{c}$

\begin{abstract}
RESUMEN
El arte en virtud de su poder simbólico puede funcionar como instrumento cognitivo y contribuir, incluso, al proceso de investigación científica, sobre todo, en sus etapas de generación de hipótesis y discusión de datos, debido a su capacidad inductora del pensamiento intuitivo y creativo. En el presente artículo, se propone un método para llevar a la práctica esta concepción, basado en la exposición de los científicos a actividades artísticas colectivas en ambientes protegidos, metodología diseñada a partir de experiencias relatadas por destacados artistas y científicos.

Palabras clave: investigación, ciencia, arte, cognición, simbolismo.
\end{abstract}

http: / / dx.doi.org/10.5546/ aap.2018.353

Texto completo en inglés:

http: / / dx.doi.org/10.5546/ aap.2018.eng.353

a. Departamento de Ciencias

Humanas, Instituto Universitario del Hospital Italiano de Buenos Aires, Argentina.

b. Universidad del Salvador-Asociación Odontológica Argentina.

c. Universidad Simón Bolívar, Facultad de Ciencias de la Salud. Barranquilla, Colombia.

Correspondencia: Dr. Carlos G. Musso: carlos.musso@ hospitalitaliano.org.ar

Financiamiento:

Ninguno.

Conflicto de intereses: Ninguno que declarar.

Recibido: 11-2-2018

Aceptado: 19-2-2018
Cómo citar: Musso C, Dricas D, GonzálezTorres H. Aplicación del arte a la investigación su utilización. Arch Argent Pediatr 2018;116(5):353-358.

\section{EL ARTE COMO INSTRUMENTO DE COGNICIÓN}

El lenguaje verbal constituye para el hombre un instrumento de abordaje cognitivo del mundo, ya que, por medio de la palabra, este logra segmentarlo en múltiples categorías (signos) que poseen el valor que les confiere su utilidad práctica y el consenso de los hablantes. Sin embargo, el hombre posee otra forma de abordaje del mundo, que se realiza a través de los sentidos, proyectando esquemas de imágenes primordiales (símbolos) provenientes de la experiencia corporal individual y de la herencia de la especie. ${ }^{1,2}$

En este sentido, Nelson Goodman y Jean-Luc Nancy sostienen que arte científica: fundamentos de un método original para y ciencia le ofrecen al ser humano distintos sistemas para ampliar el conocimiento, pues le brindan la posibilidad de percibirse a sí mismo y, desde allí, darle forma al mundo., Jacques Rancière sostiene que el arte contribuye a "diseñar nuevas configuraciones de lo visible, decible y pensable", que permite conocer desde el no saber al propiciar la creatividad. Desde la teoría de la "educación por el arte", no se trata de hacer de los científicos artistas, sino de acercarles los lenguajes artísticos durante su proceso de investigación, a través del estímulo de la sensibilización, la experimentación y la imaginación creadora. Como pregona el "arte conceptual", lo principal no es el objeto físico producido, sino los conceptos e ideas que lo originaron y emergen de él. ${ }^{5}$ Charles Percy Snow señala la perjudicial separación que actualmente padecen ciencia y arte, con la consecuente limitación al desarrollo cultural. ${ }^{6}$ Por esta razón, desde finales del siglo pasado, comenzó la incorporación de seres vivos a las expresiones artísticas, así como las producciones colaborativas entre artistas y científicos en los laboratorios de biotecnología. ${ }^{7}$ En este contexto, las discusiones contemporáneas en torno al método de las ciencias (Morin), la pregunta de qué es ciencia (Khun), la interdependencia entre el mundo interior y el laboratorio (Latour) dan cuenta de un nuevo modo de producción del conocimiento (Fried Schnitman). ${ }^{8-11}$

De lo antes expuesto, se desprende que los fundamentos que separan el 
arte de la ciencia son sus diferentes estrategias para conocer (representar) el mundo, de modo que sus contextos discursivos estarían basados en distintas pretensiones referenciales: verificables en el caso de la ciencia y metafóricas en las artes. Sin embargo, el mundo que exploran es el mismo, por lo cual sus diferencias metodológicas, lejos de justificar su falta de colaboración, remarcan sus potenciales beneficios. ${ }^{12}$

\section{II.a. EL ARTE COMO INSTRUMENTO DE INVESTIGACIÓN: SUS FUNDAMENTOS Arte y filosofía}

El arte posee características que avalan su uso en la investigación, tales como su correspondencia con el lenguaje natural, su función de disparador externo y su rol en la cognición afectiva., ${ }^{2,13-15}$

El filósofo Friedrich Schelling sostiene que la naturaleza se expresa a través de sus configuraciones, donde el concepto vive en la forma, y es esta el idioma del mundo natural (Schelling-Maturana). Las leyes del mundo natural operan calladamente y solo pueden develarse cuando afloran a la conciencia humana. Schelling sostiene que las formas simbólicas del arte pueden lograr poner de manifiesto esta conexión entre naturaleza y psiquis, a través de su materialización durante la expresión artística, ya que lenguaje natural y artístico se basan ambos en la imagen. Se establece, entonces, un círculo interpretativo en el que la naturaleza encierra en la forma el concepto, y se devela este a la conciencia a través del símbolo artístico. ${ }^{13,14}$

Según el biólogo Maturana, el sistema nervioso opera haciendo correlaciones internas e independientes del entorno (sistema cerrado), de modo que, si bien existen estímulos externos (imágenes y palabras), el organismo no actúa como consecuencia de dichos estímulos, sino como consecuencia de su propio operar gatillado por ellos. Los estímulos externos más que generadores de conductas serían disparadores de conductas pre-existentes en estado latente (plegado) que luego se expresarían (desplegado). Las imágenes del arte (símbolos) ejercerían un efecto disparador de programas internos, percibidos como intuiciones o certezas interiores. ${ }^{14,15}$

La emoción impregna siempre el proceso cognitivo y constituye un ingrediente fundamental de él. Esto se debe a que la razón es incapaz de determinar enteramente las creencias y acciones del hombre, por lo que dicha carencia es completada por la emoción (Dewey), al delimitar esta el rango de información que la razón tiene en cuenta para analizar, de modo que la emoción es portadora de relevancia y establece los objetivos y los límites de todo razonamiento. Además, la emoción es promotora de heurísticas, creatividad e innovación. Entre los mecanismos heurísticos del arte, se encuentra la capacidad metafórica, basada en la fusión de imágenes previas a fin de obtener imágenes nuevas, que permite así trascender fronteras conceptuales. El arte al evocar la emoción contribuye, entonces, a direccionar y fecundar el pensamiento científico. ${ }^{15,16}$

\section{Arte y creatividad}

Según John Dewey, cuando el hombre concibe, produce y/o disfruta de una obra de arte, surge de sí (intuición) la capacidad de distinguir lo estético, lo que da lugar a una experiencia significativa, que propicia el análisis y la reflexión. Por lo tanto, desde esta cosmovisión, las artes ocupan un lugar central dentro de la cultura, y sus productos no son meros objetos de ornamentación y/o especulación financiera, sino, fundamentalmente, promotores del desarrollo humano. ${ }^{17}$

Hans-Georg Gadamer considera que, en la experiencia estética, se dan los mecanismos hermenéuticos de comprensión, interpretación y aplicación. A través de ella, la persona toma conciencia de su horizonte interpretativo $y$, desde allí, sale al encuentro de lo que transmite la obra de arte, por lo que puede ocurrir, entonces, la fusión entre ambos horizontes. La persona compara lo nuevo que recibe de la obra con lo de otras obras, lecturas y experiencias pasadas. Se replantea, por consiguiente, el pasado a través de su situación presente y explora estrategias para modificar lo establecido a fin de generar algo nuevo. En esta fusión de horizontes, ocurre un diálogo, un intercambio de preguntas y respuestas. Al aceptar que existe una pregunta, se identifica que hay algo cuestionable, se reexaminan opiniones y se propicia la construcción de nuevos conceptos. ${ }^{18}$

David Perkins sostiene que el acto creativo, tanto en ciencia como en arte, es una extensión natural de las capacidades mentales cotidianas: percepción, entendimiento, memoria, etc. Es decir, que las personas creativas no poseen capacidades intelectuales diferentes, sino que, a partir de los mismos recursos que el resto de la gente, llegan a soluciones innovadoras. Asimismo, este autor considera que, a través de la práctica del diseño, se puede innovar, pues la capacidad para diseñar 
es una característica presente en la mayoría de la población. Esto sugiere un modelo inductor del pensamiento creativo basado en el diseño, el cual permitiría separar y reagrupar mentalmente las cosas para generar nuevas ideas. ${ }^{19}$

Finalmente, Gastón Bachelard, sostiene que la dificultad para captar un fenómeno nuevo se debe a las condiciones psicológicas generadas en el individuo por los conocimientos previos. En su opinión, es imposible hacer tabla rasa de los conocimientos previamente adquiridos, y se requiere esfuerzo para desplazar ciertas trabas que ofuscan la mente, dificultan la percepción del problema y/o la búsqueda de soluciones a él. Las prácticas artísticas contribuirían a disipar estas trabas mentales. ${ }^{20}$

\section{II.b. EL ARTE COMO INSTRUMENTO DE INVESTIGACIÓN: SU METODOLOGÍA}

A lo largo de la historia del arte, se ha documentado reiteradamente como este ha logrado obtener nuevas perspectivas interpretativas y descripciones de los fenómenos del mundo mucho antes de que lo hiciera la ciencia. ${ }^{21}$ Incluso, arte y ciencia se sirven de heurísticas comunes al momento de crear estilos o postular hipótesis de trabajo, respectivamente. ${ }^{2}$ En función de lo expuesto, es que, en el presente artículo, se propone integrar ambas formas de abordaje cognitivo (sígnico y simbólico) a fin de enriquecer y potenciar la investigación científica. Esta postura epistemológica se basa en la hipótesis de que, al funcionar el arte como un disparador de certezas interiores, es decir, de un saber del mundo que reside en el inconsciente humano por el solo hecho de ser el hombre parte constitutiva del mundo, podría contribuir a que este conocimiento aflorara al plano consciente (Wittgenstein). ${ }^{22}$ Es precisamente desde esta concepción que se propone que las imágenes cargadas de simbolismo del arte podrían activar cadenas asociativas que llegasen a propiciar el surgimiento de ideas innovadoras durante el proceso de investigación, de modo que funcionasen como "llaves" capaces de abrir portales del inconsciente. ${ }^{1,2}$

En cuanto a cómo aplicar concretamente esta propuesta a la actividad investigativa (método), existen procedimientos descritos por el pintor Salvador Dalí y el psiquiatra Carl Jung que podrían tomarse como modelo, así como una serie de imágenes ancestrales de alto contenido simbólico, es decir, con gran capacidad de funcionar como disparadores externos, descritas por la psicología, la antropología y el arte, las cuales podrían contribuir a crear una atmósfera creativa (Perkins-Nachmanovitch), sustrato fundamental en la elaboración de un método capaz de integrar el arte a la investigación científica. ${ }^{16,21-32}$

\section{El método paranoico-crítico (Salvador Dalí)}

Salvador Dalí desarrolló un método investigativo basado en el arte, al cual denominó "paranoico-crítico". Este consiste en la observación de diversas imágenes, en la que el pasaje espontáneo de una imagen a otra se realiza a través de asociaciones metonímicas (desplazamiento de una idea a otra) o metafóricas (arribo a ideas nuevas por fusión de ideas antiguas), sin ningún control de la razón, de la estética o de la moral. Se trata de un dejarse sugestionar por las formas, un proceso en el que una imagen lleva a la otra, y así sucesivamente, hasta descubrir el secreto oculto de lo que se investiga.

Dalí demostró la efectividad de este método cognitivo cuando realizó su famoso análisis del cuadro El Ángelus, de Millet (Figura 1). Éste muestra a dos campesinos que detienen su trabajo rural vespertino para elevar una plegaria. A Salvador Dalí siempre le pareció que guardaba un significado oculto y se dispuso a descubrirlo, ideando un método para lograrlo. Fue así que comenzó observando distintos tipos de piedras, tanto menhires en Finisterre como guijarros de la playa en Cadaqués, cuyas formas irregulares le eran sumamente evocadoras de la pareja de El Ángelus. Percibió luego en su imagen un signo de muerte, idea que se reforzó al experimentar pictóricamente en reiteradas oportunidades con la imagen de la pareja. Por último, intuyó el significado oculto del cuadro: la plegaria de la pareja estaba dedicada a su hijo muerto y enterrado. Un posterior análisis radiográfico del cuadro hecho por el Museo del Louvre demostró la presencia de un pequeño ataúd a los pies de la campesina, y una investigación epistolar documentó que Millet había borrado la imagen de dicho ataúd por consejo de un amigo que le había dicho que los cuadros de temas melodramáticos ya no estaban de moda en París. ${ }^{2}$

Cabe señalar que la visualización de imágenes cinematográficas podría oficiar como una "máquina inductora de pensamiento paranoico-crítico", ya que una película, merced al realismo de sus imágenes, posee la capacidad de hacer pensar y despertar la conciencia. Sin embargo, tendría que ser una 
película con mínimo montaje cinematográfico, ya que, como señala Benjamín, el montaje, lejos de estimular la liberación del pensamiento, lo condiciona al sobre determinar el sentido. Por esta razón, un film estimulante del pensamiento asociativo libre debería remedar un sueño o una película de género surrealista, donde el montaje fuese reemplazado por el "mostraje" (Deleuze). ${ }^{24}$

\section{El método alquímico (Carl Jung)}

Según Carl Jung, el opus alquimicum u obra de los alquimistas medievales no consistía en la búsqueda del oro material a partir de metales no preciosos, sino, en realidad, en la obtención del conocimiento, no solo por lo que podían aprender de los experimentos químicos que realizaban, sino, fundamentalmente, por la proyección de contenidos psíquicos que el ejercicio de la práctica alquímica les permitía alcanzar al estimular la aparición de esclarecedoras intuiciones. El lema de los alquimistas medievales era: "Nuestro oro no es el oro del vulgo" (aurum nostrum non est aurum vulgi), pues el "oro" que perseguían no era material (metal), sino espiritual (conocimiento). Durante el experimento, el alquimista proyectaba su inconsciente a la materia y volvía manifiesto involuntariamente (proyección) lo inconsciente (emergentismo). El mismo Jung aplicó estos principios al emplear la práctica de la escultura en piedra como medio para desarrollar sus teorías psicológicas.
Además, Jung describió la existencia de una serie de imágenes que constituían símbolos oníricos clásicos, capaces de propiciar también el fenómeno de proyección psíquica antes mencionado. Se destacaron entre estos diseños figuras geométricas (círculo, espiral, triángulo, cuadrado, rombo, cruz, zigzag), colores (blanco, negro, amarillo, rojo), imágenes de la Tierra y del firmamento (mar, arco iris, sol, luna, cielo, montaña, caverna, abismo), seres vivos (árbol, flor, serpiente, ave, fiera, jardín), obras ingenieriles (escalera, camino, palacio, fuente, reloj) y figuras arquetípicas (padre, madre, ángel, demonio, muerte). ${ }^{15}$

No es casual que la inmensa mayoría de las imágenes onírico-arquetípicas descritas por Jung como capaces de estimular la proyección de los saberes inconscientes (disparadores) coincidan precisamente con aquellas que la mente neolítica plasmó en las pinturas rupestres, los chamanes refieren percibir durante sus experiencias extáticas y las artes visuales han empleado como parte de su lenguaje a lo largo de la historia universal. ${ }^{26-32}$ Todos estos son símbolos arcanos, que podrían funcionar como verdaderos puentes entre el inconsciente (saber oculto) y la materia (producciones artísticas). Durante su pasaje, se daría lugar a un proceso de transformación (método alquímico) del cual resultaría el arribo de dicha información a la conciencia (saber develado).

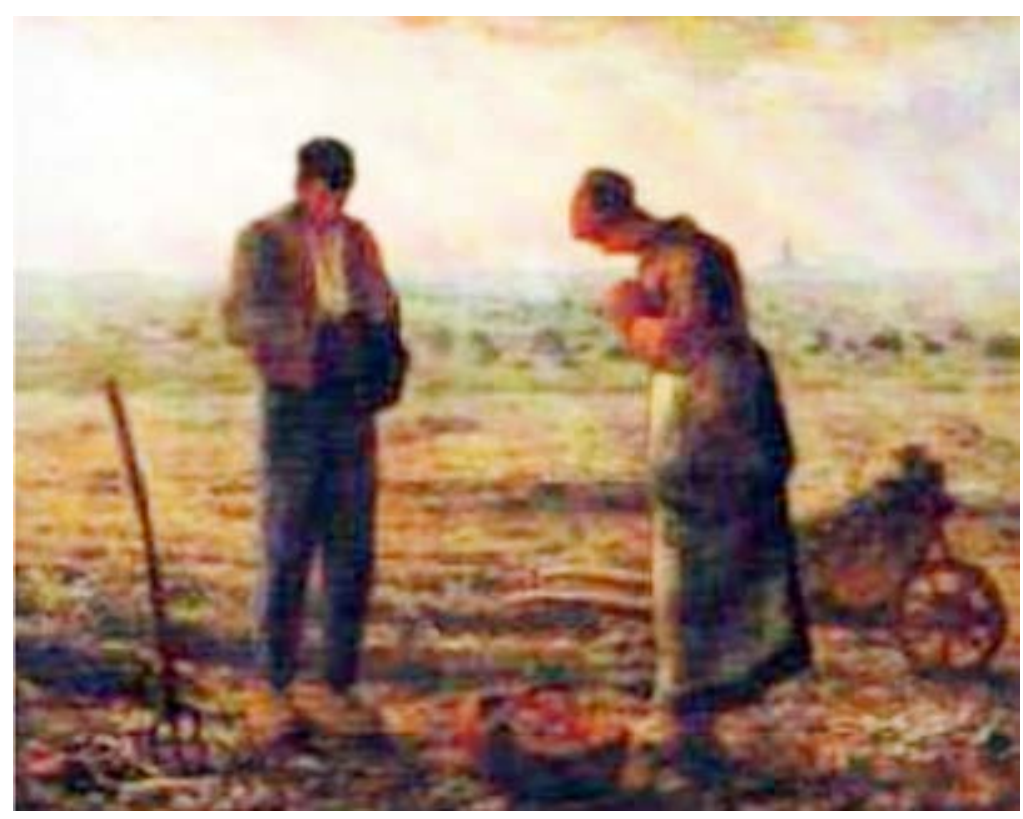


El físico Wolfgang Pauli y Carl Jung, basados, en parte, en las ideas del biólogo Paul Kammerer y el filósofo Arthur Schopenhauer, han atribuido (hipótesis) la súbita y transitoria aparición de una correspondencia entre la concientización de un saber inconsciente y la percepción de una imagen externa a la mente a la existencia de una supuesta ley de correspondencia, basada en patrones de comportamiento que regulan el mundo natural y propician estas coincidencias significativas, que serían la base del pensamiento intuitivo. ${ }^{15}$

\section{La atmósfera creativa de Perkins-Nachmanovitch}

El pensamiento creativo puede surgir tanto del ámbito externo al individuo (medioambiente o situaciones) como de su interior; por ende, deben eliminarse las barreras que pudiesen bloquearlo.

David Perkins destaca la necesidad de construir un ambiente propicio para que las prácticas artísticas puedan promover experiencias cognitivas amplias, revisar distintos puntos de vista $y$, de ese modo, elaborar reflexiones originales y creativas. Si bien la creatividad implica poner en práctica nuevas ideas en un proceso de investigación y reflexión, para que esto suceda, debe estar presente el objeto arte o se debe realizar alguna práctica artística, para lo cual se requiere un anclaje fuerte sensorial en una atmósfera afectiva que lo potencie. ${ }^{33}$

Según Stephen Nachmanovitch, el campo de acción para que surja la creatividad debe estar mediado por el juego, la exploración y la experimentación. En el caso del juego, se considera que no es importante lo que se hace, sino cómo se lo hace, en un ambiente donde ocurra una interacción comunicativa flexible, sensible y donde haya una tolerancia a los errores $\mathrm{y}$ a las situaciones ambiguas. ${ }^{34}$

\section{Una nueva propuesta metodológica}

Teniendo en cuenta los pasos clásicos del método científico (a saber: detección del problema, elaboración de la hipótesis explicativa, elección del material y del método con el que se intentará falsear la hipótesis, realización del estudio, obtención de los resultados, discusión de estos y, finalmente, obtención de la conclusión) y sabiendo a partir de lo previamente analizado que la potencial utilidad del arte en la investigación científica consistiría en facilitar que emergieran a la conciencia intuiciones capaces de dar respuesta a los interrogantes en estudio, resulta, entonces, razonable determinar que los pasos del proceso de investigación que más se beneficiarían de la influencia del arte serían aquellos que más necesitarían del pensamiento creativo, vale decir, la generación de la hipótesis y la discusión de los datos obtenidos. Sobre la base de las experiencias previas descritas por Salvador Dalí y Carl Jung, y el concepto de atmósfera creativa de Perkins y Nachmanovitch, se propone que, al momento de diseñar una metodología que permita poner en práctica estos conceptos, imbricarlos en el proceso de investigación y poder someterlos a evaluación, se emplee la siguiente metodología:

Durante el período en que el investigador estuviese elaborando la hipótesis de su investigación o de la discusión de los datos obtenidos, este debería hacerlo junto con otros investigadores, no necesariamente de su misma disciplina, compartiendo un ambiente donde todos ellos se hallasen expuestos a distintas obras de arte y/o realizasen diversas prácticas artísticas, a fin de propiciar el pensamiento intuitivo, creativo e innovador. Dicha exposición podría lograrse mediante el diseño de un ambiente protegido, en sitios preferentemente ubicados en entornos naturales (Schelling, Heidegger) y equipados para este fin, en los cuales los investigadores pudieran compartir una serie de actividades, no excluyentes entre sí, tales como:

- Realizar actividades plásticas (pintura, dibujo, cerámica, etc.).

- Escuchar piezas musicales pertenecientes a grandes compositores.

- Presenciar la proyección de películas de alto contenido simbólico.

Con respecto a este último recurso, podrían crearse cortos diseñados ex profeso con imágenes de la naturaleza o culturales de alto contenido simbólico.

El poder constatar la existencia de una producción científica significativamente mayor y más original por parte de los científicos que hubiesen estado expuestos a la influencia de este tipo de prácticas artísticas en ambientes protegidos podría corroborar la utilidad de introducir el arte en el proceso de investigación científica.

Se concluye que el arte, en virtud de su poder simbólico, cognitivo e innovador, es estimulante del pensamiento creativo y podría contribuir a optimizar las etapas de elaboración de hipótesis, diseño de la pregunta de investigación y discusión de los resultados dentro del proceso de investigación científica, para lo cual se propone en 
forma original un método basado en la exposición de los científicos a actividades artísticas colectivas en ambientes protegidos y acondicionados para tal fin.

\section{REFERENCIAS}

1. Musso CG. La intersección de las paralelas: arte y ciencia en un único proceso cognitivo. Hacia una nueva forma de investigar. Rev Hosp Ital B Aires 2012; 32(1):1-2.

2. Castro S, Marcos A. Arte y ciencia. Mundos convergentes. Madrid: Plaza y Valdés; 2010.

3. Goodman N. Maneras de hacer mundos. Madrid: Hackett Publishing; 1990.

4. Nancy JL. El artehoy. Buenos Aires:Prometeo Libros;2015.

5. Rancière J. El espectador emancipado. Pontevedra: Ellago; 2012.

6. Snow CP. Las dos culturas. Buenos Aires: Nueva Visión; 2000.

7. Machado A. El paisaje mediático. Sobre el desafío de las poéticas tecnológicas. Buenos Aires: Nueva Librería; 2009.

8. Morin E. El método III El conocimiento del conocimiento. Madrid: Cátedra; 1999.

9. Kuhn T. La estructura de las revoluciones científicas. México: Fondo de Cultura Económica; 2004.

10. Latour B. Nunca fuimos modernos. Ensayo de antropología simétrica. Buenos Aires: Siglo XXI; 2007.

11. Fried Schnitman D, Schnitman J.Resolución de conflictos. Nuevos diseños, nuevos contextos. Buenos Aires: Granica; 2000.

12. Ricoeur P. Historia y narratividad. Barcelona: Paidós; 1999.

13. Schelling F. La relación del arte con la naturaleza. Madrid: Globus; 2012.

14. Maturana-Romesín H, Pörksen B. Del ser al hacer. Los orígenes de la biología del conocer. Buenos Aires: Gránica; 2015.

15. Musso CG, Baez F, Elias MJ, et al. The principle of synchronicity-equivalence and chronomedicine: relevance and methodological exploration. Arch Argent Pediatr 2017;115(4):309-10.
16. Musso CG, EnzP. Semiótica médica. Principios lingüísticos y comunicacionales de uso médico. Buenos Aires: Delhospital ediciones; 2007.

17. Dewey J. El arte como experiencia. Barcelona: Paidós; 2008.

18. Gadamer HG. Verdad y método Fundamentos de una Filosofía, Hermenéutica, Obras completas. Tübingen:Mohr; 1986.

19. Perkins D. Las obras dela mente. México: Fondo de Cultura Económica; 1988.

20. Bachelard G. La formación del espíritu científico. Contribución al psicoanálisis del conocimiento objetivo. México: Siglo XXI; 2000.

21. Leherer J. Poust y la neurociencia. Barcelona: Paidós; 2010.

22. Wittgenstein L. Investigaciones filosóficas. Barcelona: Crítica; 2004.

23. DalíS. El mito trágico de "El Ángelus" de Millet. Barcelona: Tusquets; 2002.

24. González D, Llevadot L, Saez Tajafuerce B. Kierkegaard y las artes. Pensar la creación. Barcelona: UOC; 2015.

25. Jung CG. Psicología y alquimia. Buenos Aires: Santiago Rueda; 1957.

26. Lewis-Williams D. La mente en la caverna. Madrid: Akal; 2005.

27. Lewis-Williams D, Pearce D. Dentro de la mente neolítica. Madrid: Akal; 2009.

28. Eliade M. El chamanismo y las técnicas arcaicas del éxtasis. México: Fondo de Cultura Económica; 1960.

29. Clothes J, Lewis-Williams D. Los chamanes de la prehistoria. Barcelona: Planeta; 2001.

30. Reichel-DolmatoffG. Orfebrería y chamanismo: Un estudio iconográfico del Museo del Oro del Banco de la República, Colombia. Bogotá: Museo del Oro; 2014.

31. Pineda Camacho R. El poder de los hombres que vuelan. Gerardo Reichel Dolmatoff y su contribución a la teoría del Chamanismo. Tabula Rasa (Bogotá) 2003; 1:15-47.

32. Arola R. Custiones simbólicas. Las formas básicas. Barcelona: Herder; 2015.

33. Perkins D. Las obras dela mente. México: Fondo de Cultura Económica; 1988.

34. Nachmanovitch S. Free Play. La improvisación en la vida y en el arte. Buenos Aires: Barrendero; 2011.

\section{Archivos hace 75 años}

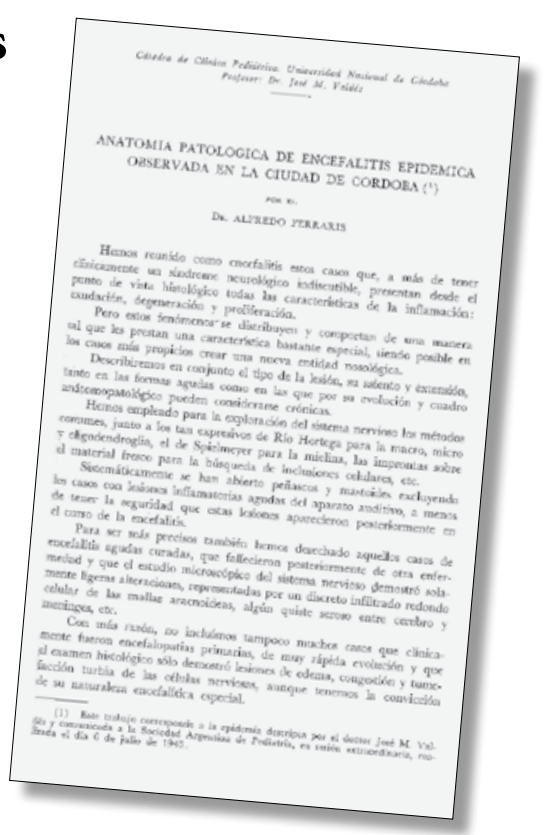

El texto completo se encuentra disponible en la versión electrónica de este número. 